\title{
Distinctive symptoms differentiate four common types of berry shrivel disorder in grape
}

\author{
by Mark N. Krasnow, Mark A. Matthews, \\ Rhonda J. Smith, Jason Benz, Ed Weber and \\ Ken A. Shackel
}

\section{Shriveled fruit in vineyards has} several origins including sunburn, dehydration, bunchstem necrosis and the recently described sugar accumulation disorder. These disorders are often confused with one another, but they can easily be distinguished by the location or composition of shriveled fruit and the condition of the rachis (the stem structure of a cluster). Sunburn is typically exhibited only on berries that are exposed to direct sunlight, and bunchstem necrosis is typified by necrotic rachis tissue. Berries with sugar accumulation disorder exhibit low sugar concentration, whereas berries with late-season dehydration typically have above-normal sugar concentration. Berries with sugar accumulation disorder and bunchstem necrosis exhibit the sugar content when sugar accumulation ceases or stem necrosis occurs, respectively. In tests, berries with sugar accumulation disorder exhibited lower berry weight, $\mathrm{pH}$ and anthocyanins, as well as differences in many nitrogenous compounds compared to normally developing fruit. In one location, sugar accumulation disorder was expressed at the whole-vine level, but none of the commonly known pathogenic organisms were found.

Shriveled berries on ripening clusters $\checkmark$ are not uncommon in California vineyards. They usually occur in only a small proportion of a vineyard's fruit (1\% to $5 \%)$, but in particular vineyards and years, shriveling can affect more
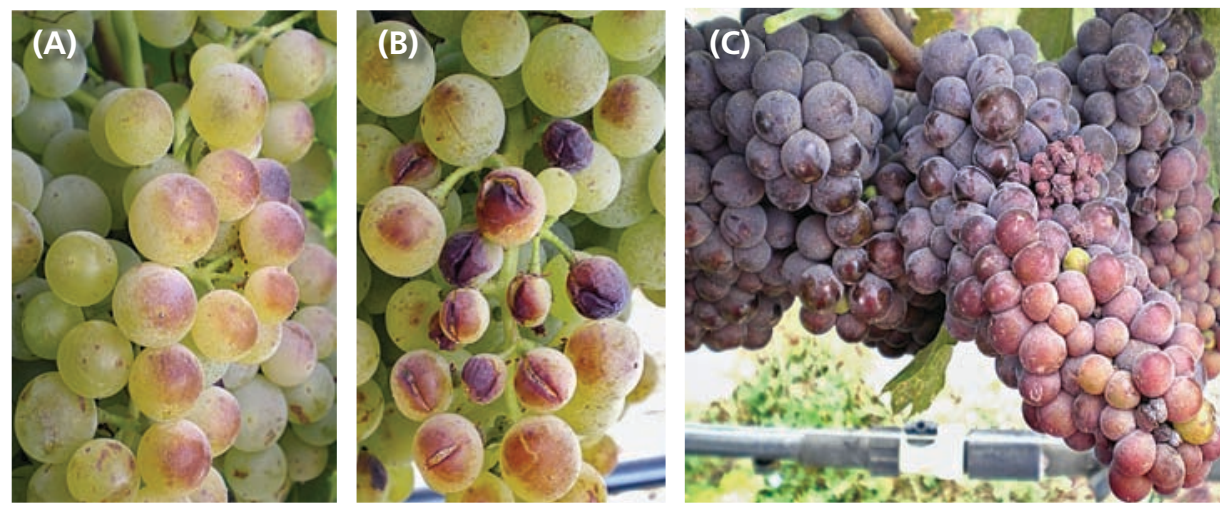

A Burger grape cluster exhibits (A) slight browning due to sunburn and (B) more severe sunburn and cracking. (C) Left, A healthy Barbera cluster and, right, a sunburned cluster with poor coloration and raisining.

than half of the crop (M. Krasnow, unpublished observation). Most shrivel disorders make the fruit less desirable for winemaking, with subsequent yield and production losses. Before taking steps to reduce the incidence of fruit shriveling in vineyards, it is necessary to differentiate between shrivel disorders. We describe four common causes of fruit shriveling and detail compositional differences between normally developing fruit and that affected by sugar accumulation disorder (SAD).

\section{Sunburn}

Fruit exposed to direct sunlight for all or part of the day, especially in the heat of the afternoon, can be damaged by sunburn, which may be caused by high temperature, ultraviolet radiation or a combination of the two (Gindaba and Wand 2005). The physical appearance of sunburned fruit depends on the grape variety and stage of development - white grapes and red grapes exposed before pigment accumulation begins (veraison) develop brown discoloration, which varies depending on severity.Veraison and early postveraison red varieties with sunburn often exhibit poor color development, and may remain pink for the remainder of the season. Post-veraison sunburn leads to fruit with less color and a shiny appearance. Sunburned berries often crack, presumably due to damaged epidermal tissues. Extreme sunburn leads to complete berry desiccation and the formation of raisins (raisining) in both red and white varieties.

Sunburn only affects berries that are directly exposed to sunlight. The nonexposed side of a sunburned cluster often develops normally. If a cluster is fully exposed to the sun on both sides, or if the rachis (the stem structure of a cluster) itself is damaged, then the cluster may be completely affected. Obvious signs of sunburn may only occur on the exposed portions of individual berries.

Sunburn can be avoided by reducing the fruit's exposure to direct sunlight, especially in the afternoon. While leaves are removed in the fruit zone in many growing regions to increase cluster exposure to indirect light, in north-south row orientations leaves are removed on the east side of the canopy to reduce direct exposure in the afternoon and the probability of sunburn. This practice does not completely eliminate the risk of sunburn, however, because morning sun can also cause damage.

\section{Late-season dehydration}

Natural dehydration is another type of shrivel that may affect berries late in ripening but prior to commercial harvest. These berries appear similar to fruit with bunchstem necrosis, but the rachis look green and healthy. For this type of shrivel, which is especially pronounced in Syrah (Shiraz), berries lose weight due to water loss, and sugars are concentrated (McCarthy 1999). Both 
increased transpiration (McCarthy and Coombe 1999) and decreased phloem (the sugar transport system in plants) influx (Rogiers et al. 2006) have been suggested as causes for late-season dehydration, but recent studies provide evidence that several varieties of grape berries remain hydraulically connected to the parent vine (Bondada et al. 2005; Chatelet et al. 2008) and therefore may lose water back to the parent plant late in ripening as well as to dry, ambient air (Keller et al. 2008; Tyerman et al. 2004).

\section{Bunchstem necrosis}

Clusters affected by bunchstem necrosis are identified by necrotic (dead) rachis tissue, with shriveled berries distal to the necrotic tissue. The visible symptoms of bunchstem necrosis begin as small black spots on pedicels (branches of the rachis that attach to berries), and progress to the lateral stem structure and rachis (Christensen and Boggero 1985). Usually, necrosis symptoms are not noted until the rachis is affected. Bunchstem necrosis may affect an entire cluster as well as the wings and tips of otherwise healthy clusters ("wings" or "shoulders" are the parts of the cluster from the first branch of the rachis; "tips" refers to the grapes farthest from the stem within the cluster). It can occur in many varieties, but is especially prevalent in Cabernet
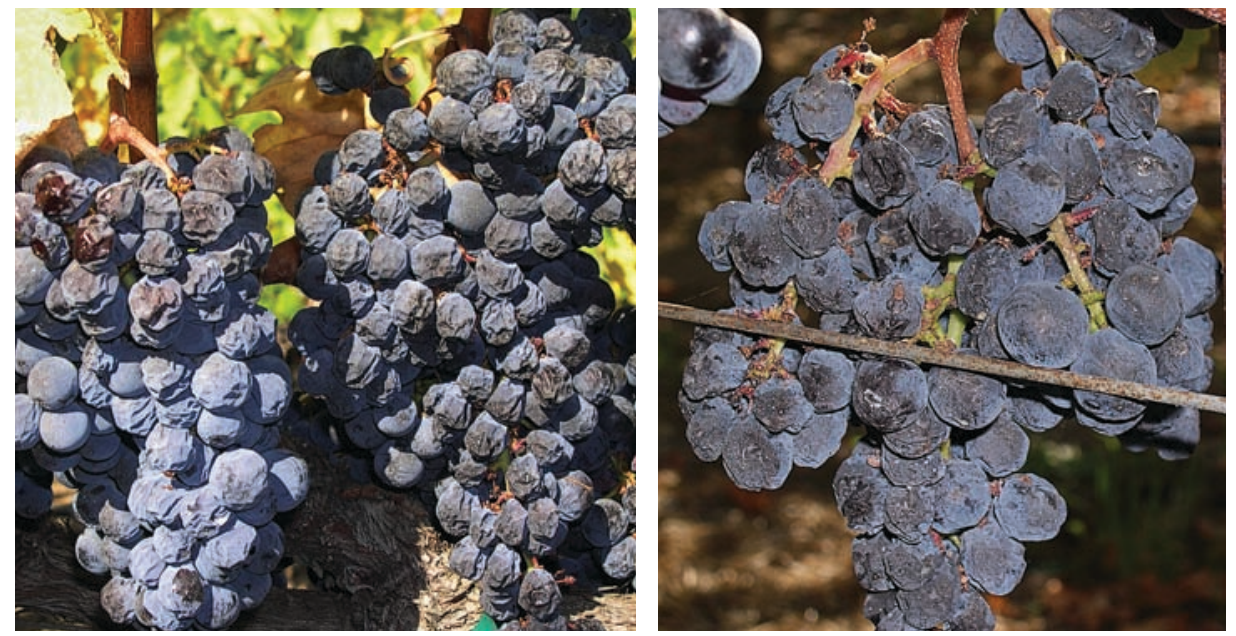

Cabernet Sauvignon clusters display late-season dehydration shrivel.
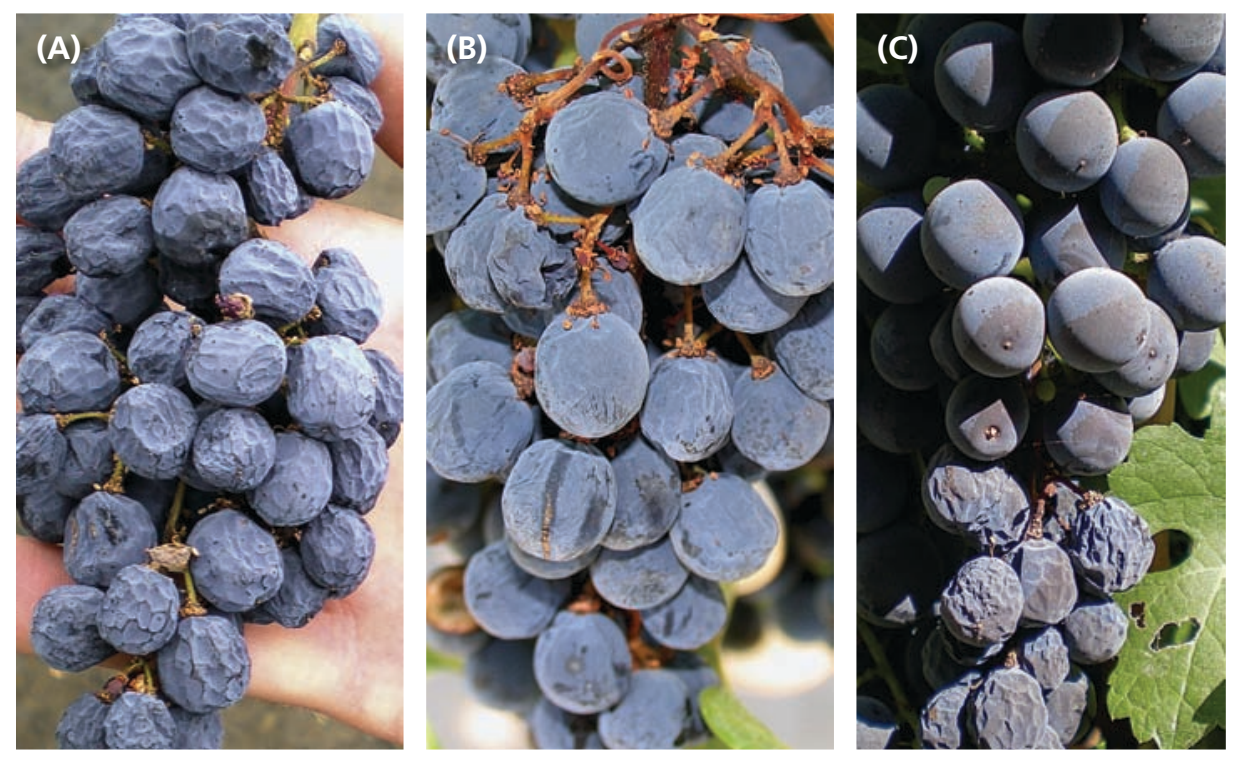

Cabernet Sauvignon clusters display bunchstem necrosis. Clusters (A) and (B) are entirely affected, and cluster (C) is affected only at the tip.
Sauvignon on California's North Coast. It has been described in the literature in many different countries, with descriptive terms that include waterberry (California), bunchstem dieback (Australia), shanking (New Zealand), stiellähme (Germany), palo negro (Chile), desséchement de la rafle (France) and dessichimiento della rachide (Italy) (Christensen and Boggero 1985).

No specific cause of bunchstem necrosis has been identified, despite many years of research. In some cases, varietal differences in susceptibility have been correlated to xylem (water transport tissue) structure, specifically a reduction on the area of xylem distal to branch points in the peduncle (bunch stem) (During and Lang 1993). The incidence of bunchstem necrosis has also been correlated to various concentrations or ratios of mineral nutrients, including magnesium, calcium, potassium and nitrogen (Capps and Wolf 2000; Christensen and Boggero 1985; Cocucci et al. 1988; Morrison and Iodi 1990; Ureta et al. 1981). Work in Chile (Ruiz and Moyano 1998) and Australia (Holzapfel and Coombe 1998) has shown that the amino acid metabolite putrescine is associated with bunchstem necrosis. More light in the canopy can also reduce bunchstem necrosis (Perez-Harvey et al. 1987; Perez-Harvey and Gaete 1986).

Bunchstem necrosis can appear very early in fruit development (around bloom) or after veraison. The terms "inflorescence necrosis" and "early bunchstem necrosis" have been used to describe bunchstem necrosis around bloom (Gu et al. 1994; Jackson and Coombe 1988, 1995). The composition of such fruit varies depending on when during fruit development the rachis becomes necrotic. Presumably, the necrosis prevents both sugar and water transport to the berry. Hence, if the rachis becomes necrotic early in the ripening period before the berry has accumulated much sugar, fruit will have low Brix (Morrison and Iodi 1990; Ureta et al. 1981). (Brix is a unit of sugar concentration; a harvest Brix of about 24 to 28 is considered normal in California viticulture.) On the other hand, if the rachis becomes necrotic after the berries 
have accumulated appreciable sugar, subsequent shriveling can concentrate the sugars. Bunchstem necrosis in Cabernet Sauvignon on the North Coast is usually the latter type. Fruit with bunchstem necrosis can have a Brix as high as 42 (unpublished data).

\section{Sugar accumulation disorder}

Another disorder with symptoms that occur during the ripening period has been called "berry shrivel"; we recently proposed that it be called "sugar accumulation disorder" (Krasnow et al. 2009). This disorder was first described in Emperor table grapes from California's San Joaquin Valley (Jensen 1970) and is characterized by poor coloration and low sugar accumulation. Sugar accumulation disorder has been found in a number of varieties and is present in many areas of California. In general, it affects only a small proportion of clusters in a vineyard, though in certain years and vineyards up to $50 \%$ of the fruit can be affected. Regardless of the variety or location, fruit affected by sugar accumulation disorder has lower $\mathrm{pH}$, berry weight and Brix compared with normally developing fruit (tables 1 and 2). When multiple rachises and fruit with sugar accumulation disorder were tested for minerals, the only consistent difference from normally developing fruit or rachises was increased calcium in the rachis tissue (Krasnow et al. 2009).

To test the hypothesis that fruit exhibiting sugar accumulation disorder may have altered nitrogen metabolism, we measured the amounts of nitrogenous compounds at harvest in fruit with the disorder compared to normally developing fruit. The vines were located at the UC Oakville Experimental Vineyard in the Napa Valley. Samples were taken at harvest on Oct. 21, 2005. Berries with sugar accumulation disorder came from clusters on six vines that historically exhibited the disorder and showed symptoms in 2005 (table 3). Normally developing berries came from clusters on three nearby vines that had no history of sugar accumulation disorder and did not display symptoms at harvest. Two berries were sampled from each cluster and eight to 10 berries were pooled to ensure enough material

TABLE 1. Composition of sugar accumulation disorder (SAD) vs. normal fruit from three sites and two different cultivars, 2007

\begin{tabular}{lcccc}
\hline \hline Sample & Fruit condition & Berry weight* & Brix & pH \\
\hline Napa Sauvignon blanc average & SAD & grams & & \\
Napa Sauvignon blanc average & Normal & 1.07 & 14.1 & 3.2 \\
Napa Cabernet Sauvignon average & SAD & 1.45 & 26.0 & 3.6 \\
Napa Cabernet Sauvignon average & Normal & 0.86 & 15.0 & 3.3 \\
Sonoma Cabernet Sauvignon & SAD & 1.03 & 21.3 & 3.5 \\
Sonoma Cabernet Sauvignon & Normal & 0.73 & 15.5 & 3.2 \\
\hline SAD average & & 1.06 & 22.8 & 3.5 \\
Normal average & & $0.90 \mathrm{a}$ & $14.8 \mathrm{a}$ & $3.26 \mathrm{a}$ \\
\hline *Means of six to 40 samples. Different lowercase letters indicate significant differences by Dunnett's test at $P=0.05$.
\end{tabular}

for analysis. Berries were peeled, their seeds removed and flesh homogenized. One milliliter of the homogenate was used for the analysis of nitrogenous compounds.

Individual amino acids in three samples of berries with sugar accumulation disorder and normally developing berries were measured at the UC Davis Molecular Structure Facility (http:// msf.ucdavis.edu/aaa.html). Briefly, juice samples were acidified with sulfosalicylic acid to precipitate any intact protein before analysis. Free amino acids were separated using a Li-citrate buffer system with ion exchange chromatography on a Hitachi L-8900 amino acid analyzer. Amino acids were quantified by a postcolumn ninhydrin-reaction detection system. Amino acid concentrations were quantified from peak areas using standard curves. Data was analyzed by ANOVA (SAS Institute, Cary, NC). Means comparisons were by Dunnett's test at $P=0.01$.

Fruit with sugar accumulation disorder from the Oakville Experimental Vineyard had significant differences in many nitrogenous compounds compared to normally developing fruit (table 4). The concentrations of some nitrogenous compounds increased while others decreased, yet the overall amount of nitrogen per berry did not significantly differ. In addition to carbohydrate metabolism, nitrogen metabolism in fruit with sugar accumulation disorder was affected, although there was no net reduction in nitrogen import. The large increase in ammonium in fruit with sugar accumulation disorder suggests interference with transamination (a reaction involving
TABLE 2. Brix, pH and berry weight of Cabernet Sauvignon berries from Oakville Experimental Vineyard used to analyze nitrogenous compounds

\begin{tabular}{|c|c|c|c|}
\hline Average & $\begin{array}{c}\text { Brix } \pm \\
\text { SD }\end{array}$ & $\begin{array}{c}\mathrm{pH} \pm \\
\mathrm{SD}\end{array}$ & $\begin{array}{c}\text { Berry weight } \\
\pm \text { SD }\end{array}$ \\
\hline & & & grams \\
\hline $\begin{array}{l}\text { Sugar } \\
\text { accumulation } \\
\text { disorder }\end{array}$ & $\begin{array}{r}17.1 \pm \\
1.7 a *\end{array}$ & $\begin{array}{l}3.47 \pm \\
0.06 a\end{array}$ & $0.97 \pm 0.08 a$ \\
\hline Normal & $\begin{array}{c}25.8 \pm \\
0.7 b\end{array}$ & $\begin{array}{l}3.70 \pm \\
0.02 b\end{array}$ & $1.29 \pm 0.14 b$ \\
\hline
\end{tabular}

TABLE 3. Compositional comparison of sugar accumulation disorder (SAD), bunchstem necrosis and normally developing fruit from Oakville Experimental Vineyard, Oct. 21, 2005

\begin{tabular}{|c|c|c|c|c|}
\hline Sample & $\begin{array}{c}\text { Berry } \\
\text { weight* }\end{array}$ & Brix & $\mathrm{pH}$ & $\begin{array}{c}\text { Sugar } \\
\text { per } \\
\text { berry }\end{array}$ \\
\hline \multicolumn{4}{|c|}{ grams } & grams \\
\hline SAD & $1.06 a$ & $18.2 \mathrm{a}$ & $3.52 a$ & $0.19 a$ \\
\hline $\begin{array}{l}\text { Bunchstem } \\
\text { necrosis }\end{array}$ & $0.98 a$ & $24.3 b$ & $3.74 b$ & $0.23 b$ \\
\hline Normal & $1.24 a$ & $24.8 b$ & $3.77 b$ & $0.31 \mathrm{c}$ \\
\hline \multicolumn{5}{|c|}{$\begin{array}{l}\text { * Data are means of } 16 \text { samples for SAD, three for } \\
\text { bunchstem necrosis and six for control. Means with } \\
\text { different letters are significantly different by Dunnett's } \\
\text { test at } P=0.05 \text {. }\end{array}$} \\
\hline
\end{tabular}

the transfer of an amino group [-NH $\left.\mathrm{NH}_{2}\right]$ between molecules) or ammonium assimilation processes (Monselise and Kost 1993).

Excess ammonium is toxic, and might account for the increased cell death observed in berries with sugar accumulation disorder compared to normally developing fruit (Krasnow et al. 2008). The reduction in phenylalanine in fruit with sugar accumulation disorder may explain its poor coloration 

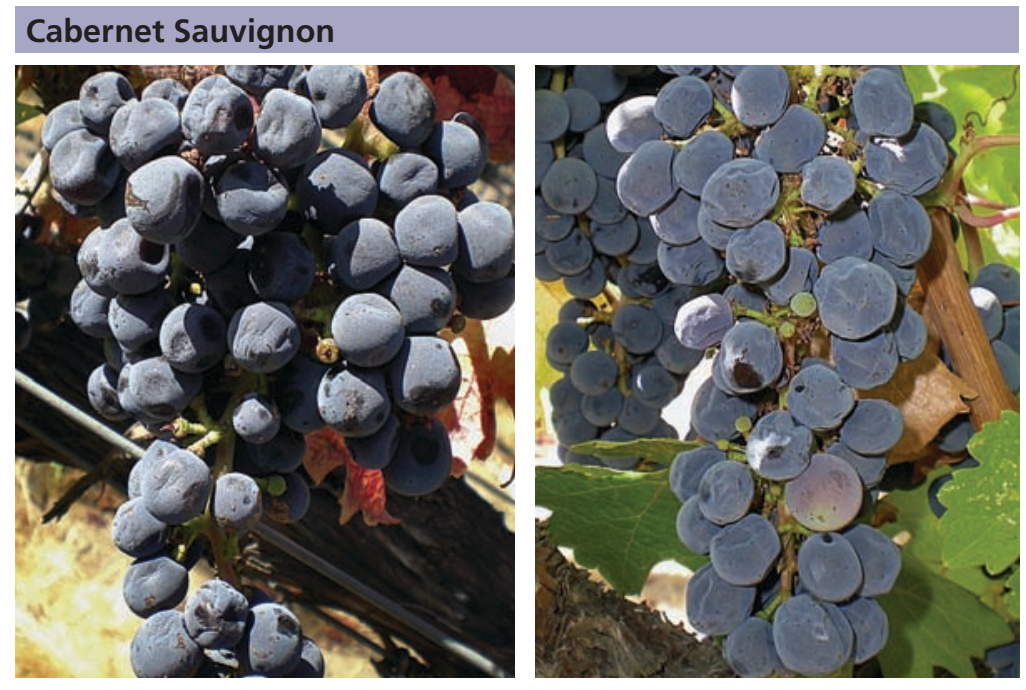

\section{Sauvignon blanc}

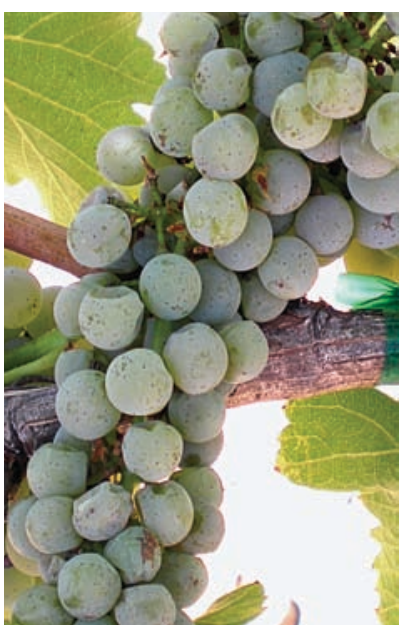

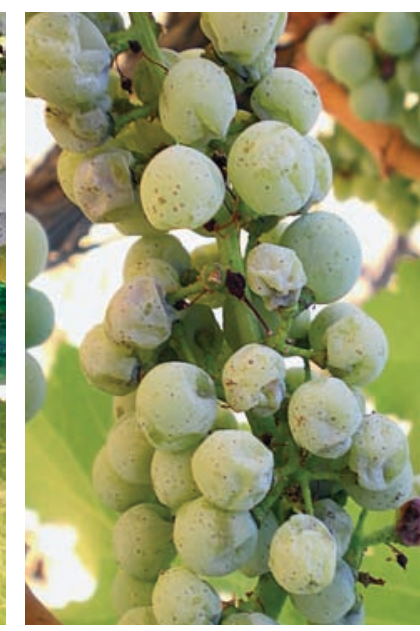

Cabernet Sauvignon and Sauvignon blanc grape clusters display sugar accumulation disorder.

(Krasnow et al. 2009), as phenylalanine is a necessary component for the biosynthesis of anthocyanins (red pigments in grapes). Likewise, an increase in the amino acid hydroxyproline may

\begin{tabular}{|c|c|c|c|}
\hline \multicolumn{4}{|c|}{$\begin{array}{l}\text { TABLE 4. Nitrogenous compounds from sugar } \\
\text { accumulation disorder (SAD)-affected and } \\
\text { normally developing Cabernet Sauvignon berries } \\
\text { at Oakville Experimental Vineyard, } 2005\end{array}$} \\
\hline Compound & SAD & $\begin{array}{c}\text { Normally } \\
\text { developing }\end{array}$ & $P$ value \\
\hline \multicolumn{4}{|c|}{ nanomoles/berry } \\
\hline \multicolumn{4}{|c|}{ Compounds decreased } \\
\hline Histidine & 6.1 & 16.6 & 0.009 \\
\hline Leucine & 20.0 & 53.4 & 0.044 \\
\hline Phenylalanine & 3.4 & 22.7 & 0.017 \\
\hline Glycine & 7.3 & 15.5 & 0.094 \\
\hline$\beta$-alanine & 18.9 & 42.9 & 0.060 \\
\hline Isoleucine & 19.8 & 47.6 & 0.055 \\
\hline Valine & 31.1 & 77.9 & 0.048 \\
\hline Ornithine & $\begin{array}{c}\text { None } \\
\text { detected }\end{array}$ & 1.6 & $N A^{*}$ \\
\hline Tyrosine & $\begin{array}{c}\text { None } \\
\text { detected }\end{array}$ & 2.3 & NA \\
\hline \multicolumn{4}{|c|}{ Compounds increasedt } \\
\hline Aspartate & 9.7 & 4.6 & 0.008 \\
\hline Alanine & 30.9 & 11.2 & 0.002 \\
\hline Ammonium & 356.0 & 168.2 & 0.031 \\
\hline Arginine & 36.5 & 3.8 & 0.029 \\
\hline Hydroxyproline & 32.3 & 18.9 & 0.010 \\
\hline \multicolumn{4}{|l|}{ Total nitrogen } \\
\hline $\begin{array}{l}\text { Nitrogen/berry } \\
(\mathrm{mg})\end{array}$ & 31.3 & 46.5 & 0.170 \\
\hline \multicolumn{4}{|c|}{$\begin{array}{l}\text { * NA = not applicable. } \\
\text { † None of the other nitrogen-containing compounds } \\
\text { analyzed (threonine, serine, glutamine, sarcosine, glycine, } \\
\text { cittruline, isoleucine, } \beta \text {-alanine, GABA, ethanolamine, } \\
\text { hydroxylysine, lysine, 1-methylhistidine and proline) } \\
\text { were significantly different between SAD and normally } \\
\text { developing fruit. }\end{array}$} \\
\hline
\end{tabular}

indicate a stress response. It remains unclear what changes in metabolism are leading to these observed differences in other nitrogenous compounds, but the fact that these differences exist suggests that both nitrogen and carbohydrate metabolism are affected by sugar accumulation disorder.

\section{Differentiating disorders}

Sugar accumulation disorder and bunchstem necrosis are often confused with one another due to the similar appearance of affected fruit. With sugar accumulation disorder, the rachis appears outwardly healthy with no signs of necrosis. These two disorders can usually be differentiated by berry composition as well. As noted, berries affected by sugar accumulation disorder have lower Brix compared to normally developing fruit, whereas

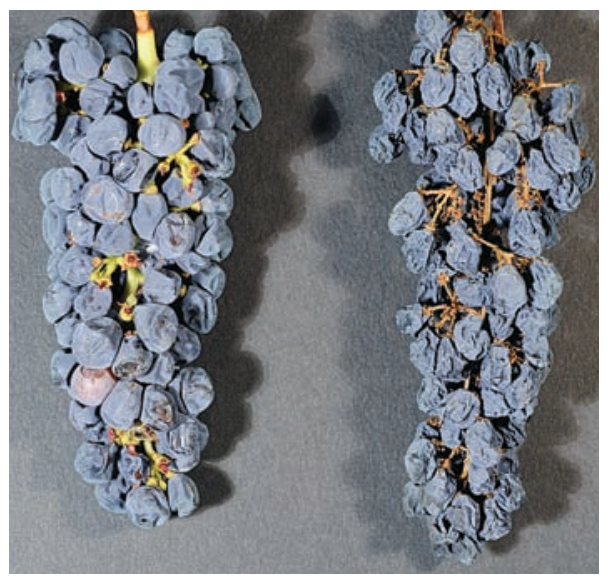

Cabernet Sauvignon clusters with, left, sugar accumulation disorder (note the healthy rachis) and, right, bunchstem necrosis. berries with bunchstem necrosis may have low to unusually high Brix depending on when in development the rachis becomes necrotic. The differences can often be large enough to distinguish by taste (M. Krasnow, personal observation).

In fact, fruit with sugar accumulation disorder stops accumulating sugar several weeks before shriveling symptoms become visible (Krasnow et al. 2009). In contrast to the shrivel of bunchstem necrosis, which can appear any time after veraison, the shrivel symptoms of sugar accumulation disorder usually appear late in ripening, several weeks to just days prior to harvest. Given these distinguishing characteristics, we suggest that the terms "sugar accumulation disorder" and "bunchstem necrosis" be adopted instead of "berry shrivel" and "waterberry," which only describe fruit appearance/flavor.

\section{Causes of sugar accumulation}

Sugar accumulation disorder appears to be a vine phenomenon at some sites (i.e., Oakville Experimental Vineyard), as nonsymptomatic clusters on vines with sugar accumulation disorder clusters had sugar levels intermediate between control and symptomatic fruit (table 5) (Krasnow et al. 2009). Although some fruit on an affected vine at the Oakville Experimental Vineyard did not exhibit shrivel symptoms, this fruit nevertheless accumulated less sugar and displayed other metabolic symptoms of the disorder, indicating that the whole vine was affected and 


\section{We suggest that the terms "sugar accumulation disorder" and "bunchstem necrosis" be adopted instead of "berry shrivel" and "waterberry," which only describe fruit appearance/flavor.}

suggesting a possible pathogenic cause. However, tests based on polymerase chain reaction (PCR) carried out by UC Davis Foundation Plant Services (http://fpms.ucdavis.edu) on these vines were negative for phytoplasmas, closteroviruses (leafroll), fanleaf viruses, nepoviruses (arabis mosaic virus) and fleck complex viruses (tomato fleck virus) (Krasnow et al. 2009).

At other sites, sugar accumulation disorder appears to affect only specific clusters, and normal-appearing clusters on the same vine are similar to those of vines without the disorder (table 5). This data suggests that there may be more than one cause of sugar accumulation disorder. It is possible that the observed symptoms (i.e., shriveling, low $\mathrm{pH}$ and poor coloration in red varieties) are an indirect result of the lack of sugar accumulation, and experiments are currently under way to test this hypothesis. Future studies will focus on tests for a causal organism of sugar accumulation disorder at the Oakville Experimental Vineyard, and a more careful examination of the metabolism of fruit affected by this disorder compared to normally developing fruit.

M.N. Krasnow is Postdoctoral Student, and M.A. Matthews is Professor, Department of Viticulture and Enology, UC Davis; R.J. Smith is UC Cooperative Extension (UCCE) Farm Advisor, Sonoma County; J. Benz is Staff Research Associate, Department of Viticulture and Enology, UC Davis; E. Weber was UCCE Farm Advisor, Napa County (deceased); and K.A. Shackel is Professor, Department of Plant Sciences, UC Davis. We appreciate the assistance of Chris Peterson and James Davids. The American Vineyard Foundation and North Coast Viticulture Research Group provided funding.
TABLE 5. Comparison of clusters on vines without sugar accumulation disorder (SAD), normal-appearing clusters from vines with SAD, and SAD clusters from Napa (2005) and Sonoma (2008)

\begin{tabular}{|c|c|c|c|c|}
\hline Location & Condition & $\begin{array}{c}\text { Juice } \\
\mathrm{pH}^{*}\end{array}$ & Brix & $\begin{array}{c}\text { Sugar } \\
\text { per } \\
\text { berry }\end{array}$ \\
\hline & & & & grams \\
\hline Napa & $\begin{array}{l}\text { Vines without } \\
\text { SAD }\end{array}$ & $3.71 a$ & $25.3 a$ & $0.350 a$ \\
\hline Napa & $\begin{array}{l}\text { Normal- } \\
\text { appearing } \\
\text { clusters on } \\
\text { vines with SAD }\end{array}$ & $3.63 a$ & $22.0 \mathrm{~b}$ & $0.282 \mathrm{~b}$ \\
\hline Napa & SAD clusters & $3.61 a$ & $19.2 c$ & $0.204 c$ \\
\hline Sonoma & $\begin{array}{l}\text { Vines without } \\
\text { SAD }\end{array}$ & $3.45 a$ & $24.0 a$ & $0.218 a$ \\
\hline Sonoma & $\begin{array}{l}\text { Normal- } \\
\text { appearing } \\
\text { clusters on } \\
\text { vines with SAD }\end{array}$ & $3.45 a$ & $23.0 a$ & $0.238 a$ \\
\hline Sonoma & SAD clusters & $3.27 b$ & $18.2 b$ & $0.127 b$ \\
\hline
\end{tabular}

*For Napa 2005 data, values are means of six samples from vines without $S A D$, six from normal-appearing clusters on vines with SAD and 16 for SAD. For Sonoma 2008 data, all values are means of 10 samples. Values from the same yea and site with different letters are significantly different by Dunnett's test at $P=0.05$.

\section{References}

Bondada BR, Matthews MA, Shackel KA. 2005. Functional xylem in the post-veraison grape berry. J Exp Bot 56:2949-57.

Capps ER, Wolf TK. 2000. Reduction of bunch stem necrosis of Cabernet Sauvignon by increased tissue nitrogen concentration. Am J Enol Viticult 51:319-28.

Chatelet DS, Rost TL, Shackel KA, et al. 2008. The peripheral xylem of grapevine (Vitis vinifera). 1.

Structural integrity in post-veraison berries. J Exp Bot 59:1987-96

Christensen LP, Boggero JD. 1985. A study of mineralnutrition relationships of waterberry in Thompson seedless. Am J Enol Viticult 36:57-64

Cocucci S, Morgutti S, Cocucci M, et al. 1988. A possible relationship between stalk necrosis and membrane-transport in grapevine cultivars. Sci Hortic 34:67-74

During H, Lang A. 1993. Xylem development and function in the grape peduncle - relations to bunch stem necrosis. Vitis 32:15-22.

Gindaba J, Wand SJE. 2005. Comparative effects of evaporative cooling, kaolin particle film and shade net on sunburn and fruit quality in apples. HortScience 40:592-6.

Gu SL, Lombard PB, Price SF. 1994. Inflorescence necrosis induced from ammonium incubation and deterred by alpha-keto-glutarate and ammonium assimilation in Pinot Noir grapevines. Am J Enol Viticult 45:155-60.

Holzapfel BP, Coombe BG. 1998. Interaction of perfused chemicals as inducers and reducers of bunch- stem necrosis in grapevine bunches and the effects on the bunchstem concentration of ammonium ion and abscisic acid. Aust J Grape Wine Res 4:59-66.

Jackson DI, Coombe BG. 1988. Early bunchstem necrosis in grapes - a cause of poor fruit-set. Vitis 27:57-61.

Jackson DI, Coombe BG. 1995. Early bunchstem necrosis - a matter of nomenclature. Am J Enol Viticult $46: 579-80$

Jensen FL. 1970. Effects of post-bloom gibberellin application on berry shrivel and berry weight on seeded Vitis vinifera table grapes. MS thesis. UC Davis. 52 p.

Keller M, Smithyman RP, Mills LJ. 2008. Interactive effects of deficit irrigation and crop load on Cabernet Sauvignon in an arid climate. Am J Enol Viticult 59:221-34

Krasnow M, Matthews M, Shackel K. 2008. Evidence for substantial maintenance of membrane integrity and cell viability in normally developing grape (Vitis vinifera L.) berries throughout development. J Exp Bot 59:849-59.

Krasnow M, Weis N, Smith RJ, et al. 2009. Inception, progression and compositional consequences of a berry shrivel disorder. Am J Enol Viticult 60:24-34.

McCarthy M. 1999. Weight loss from ripening berries of Shiraz grapevines (Vitis vinifera L. Cv. Shiraz). Austr J Grape Wine Res 5:10-6.

McCarthy M, Coombe B. 1999. Is weight loss in ripening grape berries cv. Shiraz caused by impeded phloem transport? Aust J Grape Wine Res 5:17-21.
Monselise EBI, Kost D. 1993. Different ammonium-ion uptake, metabolism and detoxification efficiencies in 2 lemnaceae - a N-15-nuclear magnetic-resonance study. Planta 189:167-73.

Morrison JC, lodi M. 1990. The influence of waterberry on the development and composition of Thompson seedless grapes. Am J Enol Viticult 41:301-5.

Perez-Harvey J, Fuenzalida M, Cornejo P, et al. 1987. Canopy management, crop level and girdling influence on waterberry incidence and fruit quality in 'Thompson seedless' cultivar. Cienc Investig Agrar 14:97-106.

Perez-Harvey J, Gaete L. 1986. Effect of light microclimate on 'Sultanina' table grape under parronal trellis system. II. Berry shattering, waterberry and Botrytis infection. Cienc Investig Agrar 13:113-20.

Rogiers SY, Greer DH, Hatfield JM, et al. 2006. Solute transport into Shiraz berries during development and late-ripening shrinkage. Am J Enol Viticult 57:73-80.

Ruiz R, Moyano S. 1998. Bunchstem necrosis in grapes and its relationship to elevated putrescine levels and low potassium content. Aust NZ Wine Ind 13:319-24

Tyerman SD, Tilbrook J, Pardo C, et al. 2004. Direct measurement of hydraulic properties in developing berries of Vitis vinifera L. CV. Shiraz and Chardonnay. Aust J Grape Wine Res 10:170-81.

Ureta F, Boidron JN, Bouard J. 1981. Influence of dessechement de la rafle on grape quality. Am J Enol Viticult 32:90-2. 